voted down a Liberal motion to create an all-party committee to draft new laws by mid-summer. Instead, the Conservatives waited until July to appoint an expert panel, before dissolving Parliament in August. Two of the three panelists have publicly opposed assisted death, raising concern about bias.

Based on this and past votes in Parliament, experts say it's clear that a new Conservative government would introduce more restrictive regulation than other parties, or possibly abdicate the task to the provinces. The issue is less contentious among the voting public: $67 \%$ of Conservatives, $75 \%$ of Liberals, $84 \%$ of New Democrats and $88 \%$ of Greens support access to assisted death for the terminally ill.

\section{Seniors care}

By 2036, people over age 65 will make up a quarter of Canada's population (up from $14 \%$ today) and account for $62 \%$ of health costs (up from about half today). The Canadian Medical Association (CMA) is leading an alliance of 50 organizations to Demand a Plan for a national seniors strategy. Its framework calls for action in six areas, from wellness to palliative and end-of-life care.

The CMA's 2015 national report card found that $89 \%$ of Canadians agree that the winner of the upcoming election needs to address the health care needs of an aging population. So, what are the parties doing?

As of Sept. 3, CMA's "promise tracker" indicated the Conservatives had pledged five-year renewal of the Canadian Partnership against Cancer and \$50 million in new funding for seniors initiatives (starting in 2017/18). In a letter to the premiers, Liberal Leader Trudeau, pledged to focus on health care issues including coping with the aging population. The Liberals had promised to provide more flexible employment insurance benefits to Canadians caring for a seriously ill family member.
The Green Party had proposed a national seniors strategy that includes a guaranteed livable income and a nationwide pharmacare program. The NDP also touted a national seniors strategy, including boosting the guaranteed income supplement by $\$ 400$ million and reversing the decision to raise eligibility for Old Age Security from 65 to 67 . The Bloc Québécois had made no promises. - Barbara Sibbald, CMAJ

With files from Lauren Vogel, Laura Eggertson, Shannon Lough and Roger Collier.

Election news primers devoted to each of the above issues include, Election 2015: Mental health needs targeted federal funds; Election 2015: Closing the Aboriginal health gap; Election 2015: The federal flipflop on pharmacare; CMA developing assisted-death guidelines and Physicians want action on seniors care.

CMAJ 2015. DOI:10.1503/cmaj.109-5152

\title{
Filling the cannabis knowledge gap
}

$\mathrm{E}$ ducating physicians on medical marijuana may improve access for patients seeking an alternative therapeutic option, but it may also mitigate some of the cultural stigma that has persisted since the drug was declared illegal in 1923.

Cannabis for medical purposes was legalized in 2001 in Canada, and in 2014 Health Canada changed the rules, making licensed health care practitioners responsible for filling out the approval document - akin to a prescription - stating the dosage and the frequency of use. But in the absence of guidelines or rigorous evidence, many doctors are uncomfortable providing access to their patients.

Now educational opportunities are emerging. The College of Family Physicians of Canada (CFPC) has approved seven programs on dried cannabis; the two online ones were funded by Tilray, a licensed producer. Another cannabis producer, Tweed Marijuana Inc., launched its education program this spring. Physicians seeking an education free of industry influence can look to the
Advancing Practice online certificate program approved by the Canadian Council on Continuing Education in Pharmacy. In addition, doctors can attend seminars or dinner lectures led by researchers or fellow doctors.

Dr. David Hepburn, a family physician in Victoria, BC, is one of the latter. Over the next few weeks, he will travel to five provinces to educate other doctors on medical cannabis. "One of the leagues about the science behind cannabis and how it works in the body. Researchers only started to describe the body's endocanabinoid system in 1990 . According to Health Canada, this system appears to regulate a host of functions in the body, including neural development, appetite, pain and cardiovascular functions.

Not so long ago, Hepburn was opposed to using cannabis, but after

\section{"I began to realize the more I educated myself that - wow - we really were misled over many years."}

things I ask physicians, in a room of about 100 doctors, is 'How many of you have cannabis in your blood system right now?' You might get one or two brave souls who put a hand up, but I say the fact is you all do because you're all making your own cannabinoids."

Over the past year and a half, Hepburn has been speaking with his col- patients told him how the drug helped them, he started signing the forms to allow his patients legal access.

"I began to realize the more I educated myself that — wow — we really were misled over many years. Sometimes it's more important to unlearn than to learn."

Making education available requires funding; Hepburn fully discloses that 
some of his seminars are backed by licensed producers of cannabis, but says this doesn't change what he says or does. "I have given talks as most specialists would have given talks on behalf of Pfizer."

Tweed, the licensed producer in Smiths Falls, Ontario, funds its own educational program, which was designed at arm's length by an external committee and was accredited by the CFPC in May.

The Tweed director of medical education, Amanda Daley, says that because of limited evidence, there's a knowledge gap. "The incentive for Tweed is to help close that gap and be seen as a partner to provide knowledge to physicians."

During 60- or 90-minute presentations, doctors learn about CFPC's preliminary guidance, the endocanabinoid system, existing evidence for inhaled cannabis and federal regulations on the use of medical marijuana. "Our program also talks about how to minimize the risk of abuse, diversion and inappropriate prescribing of cannabis for medical purposes," Daley says.

Between May and June, 1700 doctors attended the Tweed-sponsored informational program at various medical conferences.

Having the industry involved in generating the content of medical education is a "slippery slope," says Dr. Chris Simpson, past president of the Canadian Medical Association (CMA). There was a lot of criticism when the pharmaceutical industry was involved in education and now that's been cleaned up and the cannabis industry is taking its turn, he adds.

"The concern is that we have one standard for pharmaceutical drugs and we have no standard whatsoever for medical marijuana."

But if the medical cannabis programs are approved by the CFPC "those I think are good," Simpson says.

He also praises the college's guidance around prescribing medical marijuana. "They're very conservative; they appropriately reflect the fact that the evidence base for medical marijuana is quite narrow and low quality — so far."

Jessica Black, the manager of accreditation at the CFPC, says programs are reviewed in accordance with recommendations from its medical marijuana

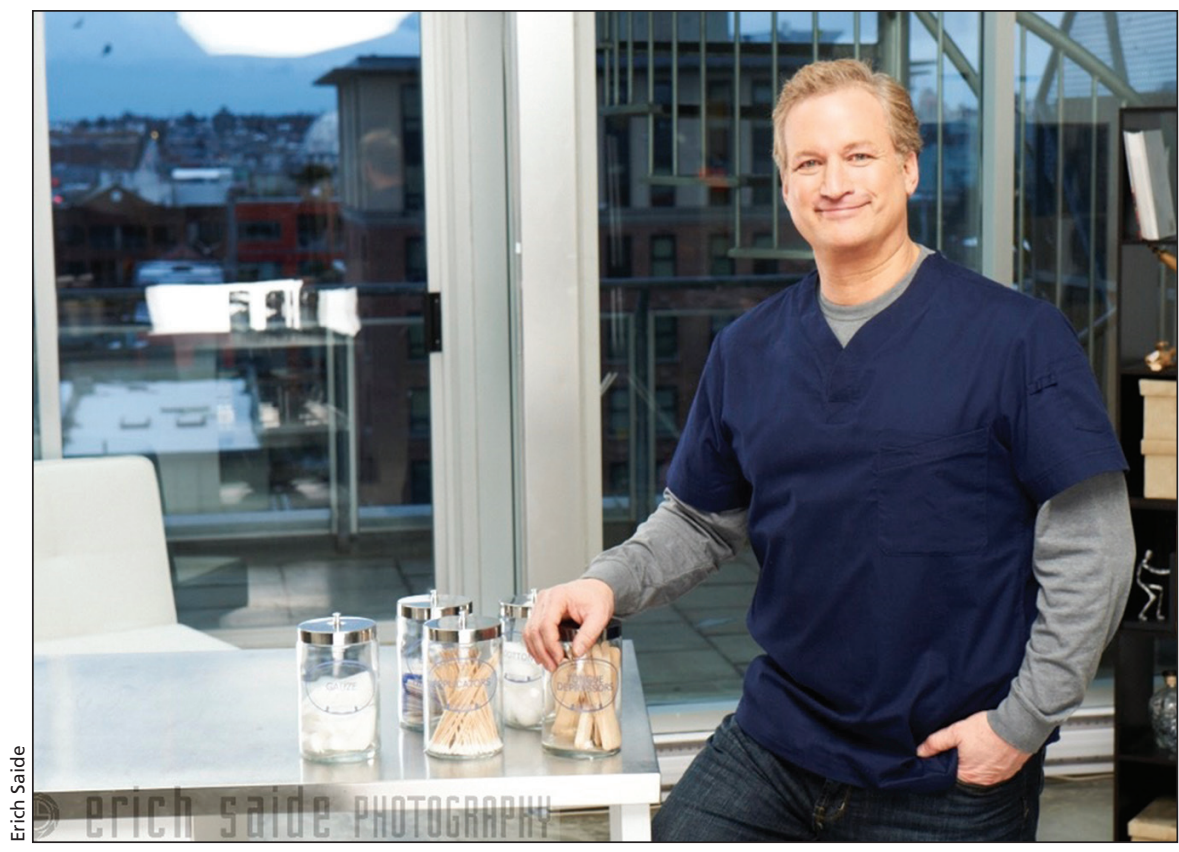

Dr. David Hepburn teaches colleagues across the country about prescribing medicinal cannabis.

review group, which screens for bias. "The content needs to be scientifically valid and that there should be evidence for any assertions or recommendations made in a program that's being delivered to family physicians."

Although many organizations have tried to provide more education, Dr. Mark Ware, the director of clinical research at the Alan Edwards Pain Management Unit at McGill, says, "I don't think any of them have met the knowledge gap fully."

Ware is also the director of the Canadian Consortium for the Investigation of Cannabinoids, a nonprofit organization that began in 2000. "We've conducted an enormous number of CME [continuing medical education] events across Canada, through different conferences, workshops, to try to help clinicians discuss and understand more about what this drug is, and what we do know and what we don't know."

Commercial CME providers are also stepping into the fray. MD Briefcase, an online education provider, has two CFPC-accredited courses funded by an unrestricted educational grant from the licensed producer Tilray. MD Briefcase also has nine-hour program that is not sponsored by industry available through Advancing Practice. It costs $\$ 900$ and includes information on history of the drug, evidence around its use, precautions in prescribing and monitoring patients.

One of the members on Advancing Practice's cannabis program's planning committee is Ian Mitchell, an emergency physician in Kamloops, British Columbia. He says he has proactively educated himself, including attending a conference in San Francisco, and is involved in an upcoming clinical study on post-traumatic stress disorder.

Mitchell's motivation is harm reduction; he prefers prescribing access to cannabis over opiates for chronic pain. "The goal is to educate physicians about cannabis and to be able to use this in their practice, particularly in their chronic pain patients, to try to decrease mortality."

A study in JAMA shows that American states with medical marijuana laws have $25 \%$ fewer deaths from opiate overdoses. In comparison, Mitchell says that cannabis is a relatively safe drug that can treat pain, but he still sees many doctors who are unwilling to discuss medical cannabis with their patients and who prefer to write scripts for painkillers like oxycontin.

"Right now physicians are the gatekeepers and if we have uneducated physicians then that gate remains closed." - Shannon Lough, CMAJ

CMAJ 2015. DOI:10.1503/cmaj.109-5141 